\title{
Cooled radiofrequency denervation for treatment of sacroiliac joint pain: two-year results from 20 cases
}

This article was published in the following Dove Press journal:

Journal of Pain Research

3 July 2013

Number of times this article has been viewed

Kok-Yuen Ho'

Mohamed Abdul Hadi

Koravee Pasutharnchat ${ }^{2}$

Kian-Hian Tan ${ }^{2}$

'Pain Management Centre, Raffles Hospital, ${ }^{2}$ Pain Management Centre, Singapore General Hospital, Singapore
Correspondence: Kok-Yuen Ho 585 North Bridge Road, Raffles Pain Management Centre, Level I3, Singapore 188770

Tel +6563112310

Fax +65 63।I 2373

Email ho_kokyuen@rafflesmedical.com
Background: Sacroiliac joint pain is a common cause of chronic low back pain. Different techniques for radiofrequency denervation of the sacroiliac joint have been used to treat this condition. However, results have been inconsistent because the variable sensory supply to the sacroiliac joint is difficult to disrupt completely using conventional radiofrequency. Cooled radiofrequency is a novel technique that uses internally cooled radiofrequency probes to enlarge lesion size, thereby increasing the chance of completely denervating the sacroiliac joint. The objective of this study was to evaluate the efficacy of cooled radiofrequency denervation using the SInergy ${ }^{\mathrm{TM}}$ cooled radiofrequency system for sacroiliac joint pain.

Methods: The charts of 20 patients with chronic sacroiliac joint pain who had undergone denervation using the SInergy ${ }^{\mathrm{TM}}$ cooled radiofrequency system were reviewed at two years following the procedure. Outcome measures included the Numeric Rating Scale for pain intensity, Patient Global Impression of Change, and Global Perceived Effect for patient satisfaction.

Results: Fifteen of 20 patients showed a significant reduction in pain (a decrease of at least three points on the Numeric Rating Scale). Mean Numeric Rating Scale for pain decreased from $7.4 \pm 1.4$ to $3.1 \pm 2.5$, mean Patient Global Impression of Change was "improved" (1.4 \pm 1.5$)$, and Global Perceived Effect was reported to be positive in 16 patients at two years following the procedure.

Conclusion: Cooled radiofrequency denervation showed long-term efficacy for up to two years in the treatment of sacroiliac joint pain.

Keywords: ablation, chronic low back pain, intervention, neurotomy, sacroiliitis

\section{Introduction}

The prevalence of low back pain is reported to be $18 \%-30 \%$, with sacroiliac joint pain accounting for up to $40 \%$ of all low back pain complaints. ${ }^{1}$ The International Association for the Study of Pain diagnostic criteria for sacroiliac syndrome include: pain in the region of the sacroiliac joint with possible radiation to the groin, medial buttocks, and posterior thigh; reproduction of pain by physical examination techniques that stress the joint; elimination of pain by intra-articular injection of local anesthetic; and an ostensibly morphologically normal joint without demonstrable pathognomonic radiographic abnormalities. ${ }^{2}$

The treatment of sacroiliac joint pain is challenging. Various treatment options include intra-articular injection of local anesthetic and corticosteroid, radiofrequency denervation, and surgical stabilization, but none has been consistently shown to provide effective and long-term pain relief. ${ }^{3}$ 
Radiofrequency denervation is a minimally invasive procedure that uses radiofrequency thermal energy to ablate the sensory nerve fibers of the sacroiliac joint, thereby interrupting nociceptive signals. Innervation of the sacroiliac joint remains a subject of much debate, but it is generally believed that the lateral branches of S1-S3 and the L4-L5 dorsal rami innervate the posterior sacroiliac joint. ${ }^{4}$ The lateral branches from S1-S3 emerge from the posterior sacral foramina and travel in a variable pattern to the sacroiliac joint. Because of the inconsistent sensory distribution to the sacroiliac joint, studies using conventional radiofrequency denervation to treat sacroiliac joint pain have produced conflicting results. ${ }^{46}$

Cooled radiofrequency is a novel technique whereby internally cooled radiofrequency probes can lead to larger lesions. ${ }^{7}$ By treating a greater area of tissue lateral to the posterior sacral foramina, the chance of disrupting the sacral lateral branches will be higher. The aim of this study is to report the long-term efficacy of cooled radiofrequency denervation for sacroiliac joint pain at two years.

\section{Materials and methods}

After institutional review board approval was obtained, a chart review was performed on 20 consecutive patients with chronic sacroiliac joint pain who had received cooled radiofrequency denervation of the sacroiliac joint at the pain management center of a tertiary teaching hospital. After introduction of this new technique of radiofrequency treatment for sacroiliac joint pain, the conventional method of radiofrequency ablation whereby bipolar lesions were created with probes placed within the sacroiliac joint was no longer offered to patients.

Patients were eligible for cooled radiofrequency denervation of the sacroiliac joint only when they met the following criteria: predominant axial pain below L5; chronic pain for more than six months; failure to achieve adequate pain relief with physical therapy or pharmacotherapy; signs and symptoms of sacroiliac joint pain on physical examination; and single positive diagnostic intra-articular sacroiliac joint injection using $3 \mathrm{~mL}$ of $0.25 \%$ bupivacaine and $20 \mathrm{mg}$ triamcinolone with more than $50 \%$ pain relief for at least six hours after the procedure. Patients who had undergone conventional radiofrequency of the sacroiliac joint previously but continued to have pain were also eligible.

Between April 2008 and June 2010, 20 consecutive patients met the inclusion criteria and gave consent for cooled radiofrequency denervation of the sacroiliac joint. The primary outcome measure was pain intensity on the Numeric
Rating Scale (NRS, with 0 being "no pain" and 10 being the "worst possible pain"). Secondary outcome measures included Patient Global Impression of Change scale (PGIC, a seven-point scale ranging from "very much improved" [+3] to "no change" [0] to "very much worse" [-3]) and Global Perceived Effect (GPE) for patient satisfaction. ${ }^{8}$ GPE was recorded based on the response to three questions, ie, "My pain is better now than before treatment", "The treatment I received improved my ability to perform daily activities", and "I am satisfied with the treatment I received and would recommend it to others". An affirmative response to all questions was considered to be a positive outcome. A negative response to any of these questions constituted a negative outcome. Statistical analysis using paired $t$-tests was performed using the Statistical Package for the Social Sciences version 17.0 software (SPSS Inc, Chicago, IL, USA).

\section{Cooled radiofrequency denervation}

The SInergy ${ }^{\mathrm{TM}}$ system (Kimberly Clark Health Care, Roswell, GA, USA) is a minimally invasive percutaneous technique that uses internally cooled radiofrequency probes. ${ }^{9}$ Radiofrequency energy is delivered from and concentrated around the electrode, generating heat in the surrounding tissue. The hollow lumina of the probes permit continuous cooling of the electrode with circulating water. These internally cooled radiofrequency electrodes act as heat sinks that remove heat from tissue adjacent to the electrode. Cooling can lead to larger lesions because it can remove heat from the tissue adjacent to the electrode tip, preventing charring of tissue and maintaining a low impedance to allow dissipation of heat to a larger area. ${ }^{7}$ As a result, lesions of a larger volume could be produced compared with noncooled electrodes. ${ }^{10,11}$ By treating a greater area of tissue lateral to the posterior sacral foramina, the chance of disrupting the lateral sacral branches will be higher.

Cooled radiofrequency denervation using the SInergy ${ }^{\mathrm{TM}}$ system was performed as an ambulatory surgical procedure using superficial local anesthesia and intravenous sedation when necessary. Intravenous access was established in the preoperative area. Pulse oximetry and automated blood pressure monitoring were used. A dispersive return electrode pad was placed on the patient on one of the lower extremities. The low back and buttock area was cleaned with povidoneiodine solution and draped in a standard sterile fashion with towels.

Using an anteroposterior fluoroscopic view with a slight ipsilateral (20 degrees) oblique tilt, the $\mathrm{S} 1, \mathrm{~S} 2$, and $\mathrm{S} 3$ posterior sacral foraminal apertures were identified and a 25 -gauge, 
3.5 inch Quincke tip needle was cautiously advanced to the most superolateral aspect of each respective neural foramen as determined by anteroposterior and lateral fluoroscopic views (Figure 1). These locations served as reference points for placement of the epsilon marker and introducer needles. The beam was returned to the starting anteroposterior fluoroscopic view and appropriate skin starting positions were identified and infiltrated with $3 \mathrm{~mL}$ of $1 \%$ lidocaine. Using the posterior sacral foraminal aperture as a "clock-face", the epsilon marker was used to guide the positions of the needle to the following locations:

- $\mathrm{S} 1$, right = 1 o'clock, 3 o'clock, and 5 o'clock; left = 11 o'clock, 9 o'clock, and 7 o'clock lateral branches

- S2, right = 1 o'clock, 3 o'clock, and 5 o'clock; left, 11 o'clock, 9 o'clock, and 7 o'clock lateral branches

- S3, right = 1 o'clock, 3 o'clock; and left, 11 o'clock and 9 o'clock lateral branches (Figure 2).

An 18-gauge SMK introducer needle was inserted under fluoroscopic guidance in a tunnel view approach sequentially onto the target positions described above until the introducer tip touched the bony surface of the sacrum. The needle tip was positioned to be approximately $10 \mathrm{~mm}$ from the lateral edge of the posterior sacral foraminal aperture as determined using the epsilon guide. The skin marker was positioned as a skin reference. Lateral views were taken to ensure proper depth of insertion. The stylet was then withdrawn from the introducer, and the 18-gauge SInergy ${ }^{\mathrm{TM}}$ radiofrequency probe was fully inserted into the introducer such that the probe tip

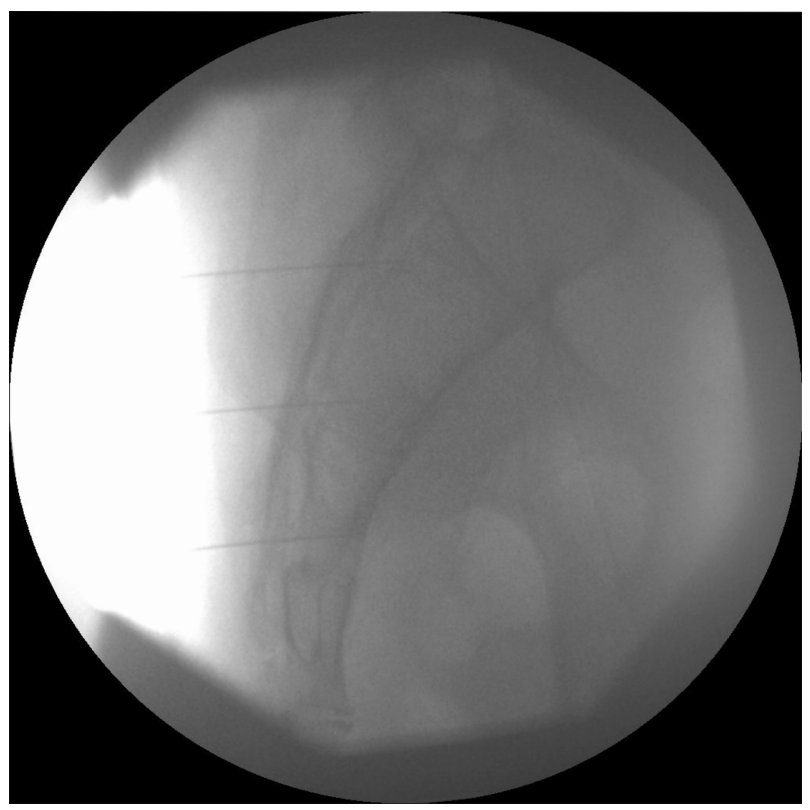

Figure I Lateral fluoroscopic view of the sacrum showing three separate 25-gauge spinal needles placed within the SI, S2, and S3 foramina.

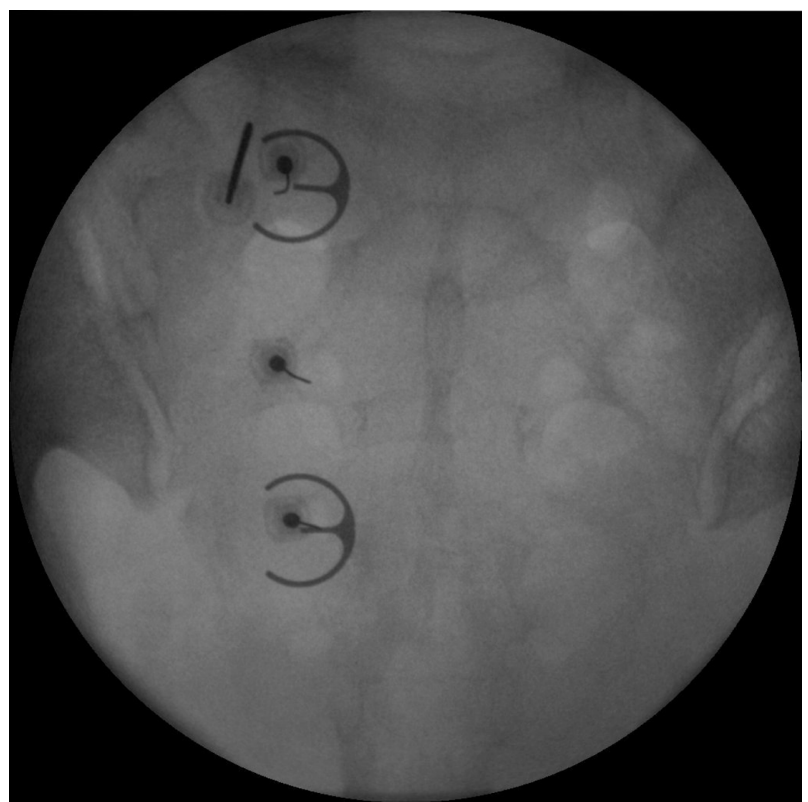

Figure 2 Anteroposterior fluoroscopic view of the sacrum showing three separate 25 -gauge spinal needles placed within the left S1, S2, and S3 foramina. An epsilon ruler is used as a guide such that the needle tip is positioned about $10 \mathrm{~mm}$ lateral to the posterior sacral foramina apertures. The radiofrequency electrode is positioned at the II o'clock position of the SI foramen.

was superficially suspended approximately $2 \mathrm{~mm}$ off the sacral bony surface. At each of the respective target positions, impedance within the range of 200-500 ohms and baseline temperature readings were obtained. Once the position was verified, $1 \mathrm{~mL}$ of $0.25 \%$ bupivacaine and $5 \mathrm{mg}$ of triamcinolone were injected at each lesion site. Radiofrequency lesioning was then carried out at a set temperature of $60^{\circ} \mathrm{C}$ for 150 seconds. ${ }^{9}$ Subsequently, the introducer and electrode were repositioned caudally in a stepwise manner to create two additional lesions along the lateral aspect of $\mathrm{S} 1$ as well as lesions lateral to the $\mathrm{S} 2$ and $\mathrm{S} 3$ posterior sacral foraminal apertures.

The respective location of the left or right dorsal rami of L5 over the sacral ala was identified using an oblique fluoroscopic view. Sensory stimulation was obtained at less than $0.5 \mathrm{~V}$ and $50 \mathrm{~Hz}$ and motor stimulation at $2 \mathrm{~Hz}$ was negative up to $1.5 \mathrm{~V}$. The $\mathrm{L} 5$ dorsal ramus was then lesioned at $60^{\circ} \mathrm{C}$ for 150 seconds.

\section{Results}

Patient baseline characteristics and outcome measures are presented in Table 1. The mean age was $54.3 \pm 15.4$ years. There were 14 female and six male patients. All patients were Asian. Five of the 20 patients had previously received conventional radiofrequency ablation of the sacroiliac joint, either at our institution or at other medical centers. 


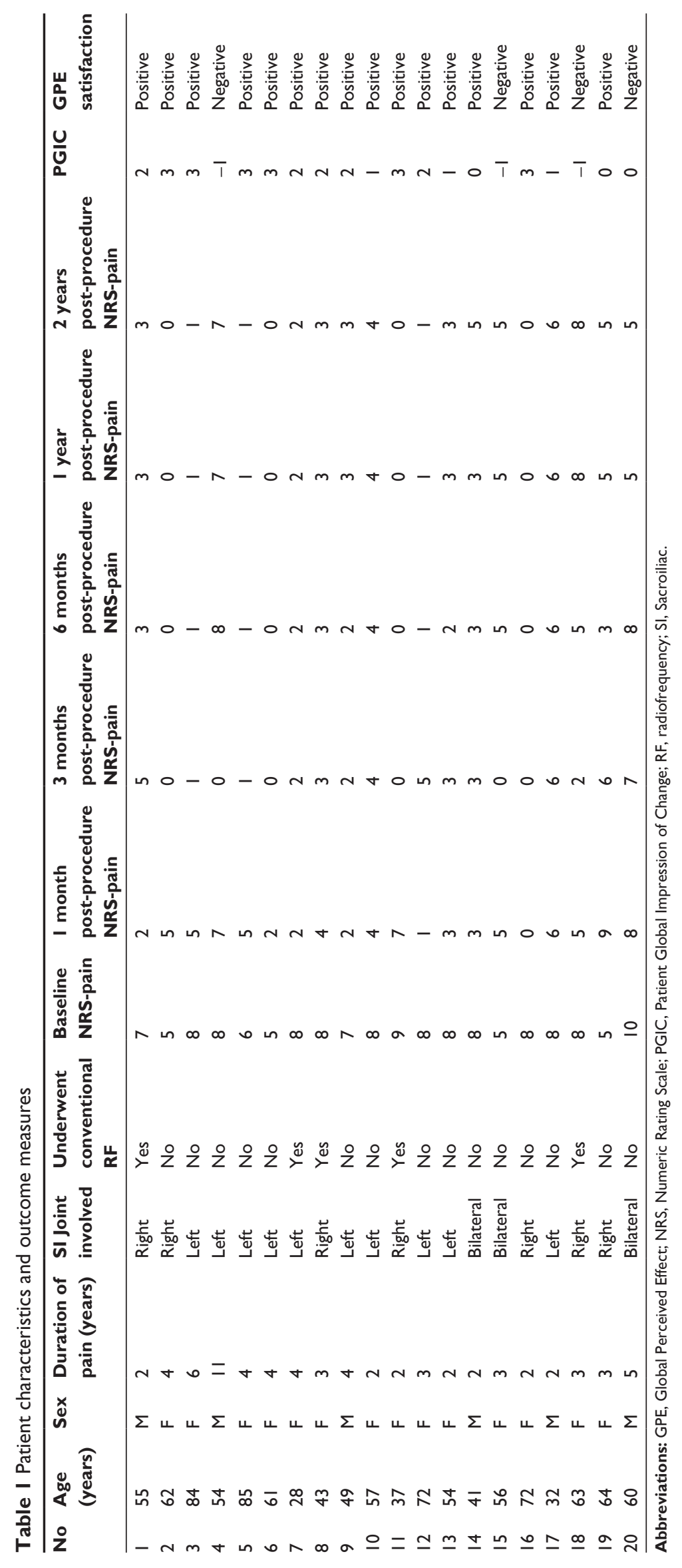


Three patients underwent bilateral sacroiliac joint cooled radiofrequency denervation. Short-term pain relief was observed, with the mean NRS pain score decreasing from $7.4 \pm 1.4$ at baseline to $4.3 \pm 2.4$ at one month and to $2.5 \pm 2.3$ at three months post-procedure $(P<0.001)$. Long-term pain relief was sustained at one and two years post-procedure, with NRS pain remaining at $3.0 \pm 2.4$ and $3.1 \pm 2.5$, respectively $(P<0.001$, Table 2).

None of the patients were consuming opioids before the procedure. Analgesics prescribed included nonsteroidal anti-inflammatory drugs, cyclo-oxygenase type 2 selective inhibitors, tramadol, and combinations of paracetamol and tramadol. Patient 18 was prescribed oral morphine when radiofrequency ablation of the sacroiliac joint failed to give her pain relief and she has since been maintained on longterm morphine therapy. Patient 20 had failed back surgery syndrome and bilateral sacroiliac joint pain, and also underwent bilateral radiofrequency denervation without success, so an intrathecal opioid delivery pump was implanted. In general, patients felt that pain was improved, and the mean PGIC score was $1.4 \pm 1.5$. GPE for patient satisfaction was positive in 16 of 20 patients. No complications or side effects were observed in any of the patients. The procedure was generally well tolerated by all patients, with postoperative soreness at the injection site for up to one week being the most common complaint.

\section{Discussion}

Results in our series of 20 patients demonstrate the long-term efficacy of SInergy ${ }^{\mathrm{TM}}$ for cooled radiofrequency denervation of sacroiliac joint pain. To the authors' knowledge, this is the only research showing long-term efficacy of this procedure at two years. Seventy-five percent of the patients showed at least a three-point reduction in NRS for pain, with a statistically significant reduction in mean pain intensity scores. This is

Table 2 Outcome measures

\begin{tabular}{|c|c|c|c|}
\hline & Mean & SD & $P$ value \\
\hline \multicolumn{4}{|l|}{ NRS-pain } \\
\hline Pre-treatment & 7.4 & $\mathrm{I} .4$ & \\
\hline \multicolumn{4}{|l|}{ Post-treatment } \\
\hline I month & 4.3 & 2.4 & $<0.001$ \\
\hline 3 months & 2.5 & 2.3 & $<0.001$ \\
\hline 6 months & 2.9 & 2.5 & $<0.001$ \\
\hline I year & 3.0 & 2.4 & $<0.001$ \\
\hline 2 years & 3.1 & 2.5 & $<0.001$ \\
\hline \multicolumn{4}{|c|}{ Patient subjective rating } \\
\hline Post-treatment PGIC & 1.4 & - & \\
\hline
\end{tabular}

Abbreviations: NRS, Numeric Rating Scale; PGIC, Patient Global Impression of Change; SD, standard deviation. considered to be a clinically relevant degree of pain relief. ${ }^{8}$ PGIC for symptom improvement was favorable and GPE for patient satisfaction was positive in $80 \%$ of patients.

Various methods of radiofrequency denervation have been reported in the literature. Ferrante et al reported use of radiofrequency denervation with bipolar electrodes for thermoablation along the sacroiliac joint line. In their study, $36.4 \%$ of patients had a $50 \%$ reduction in pain for a period of at least six months. ${ }^{5}$ Vallejo et al used pulsed radiofrequency denervation of the medial branch of L4, posterior ramus of L5, and lateral branches of S1 and S2. Seventy-three percent of their patients had more than $50 \%$ pain relief for 6-32 weeks. ${ }^{12}$ In a pilot study, Cohen and Abdi performed radiofrequency denervation at the medial branch of L4, the dorsal rami of L5, and the lateral branches of S1-S3 in their patients with sacroiliac joint pain. Eight of nine patients had more than $50 \%$ pain relief that lasted for more than nine months. ${ }^{13}$ Discrepancies in the success rates for radiofrequency denervation of the sacroiliac joint may be related to the different techniques used or to anatomic variation of the sensory fibers innervating the sacroiliac joint. Yin et al reported that anatomic locations of the lateral sacral branches exited the sacral foramen between the 2 o'clock and 6 o'clock positions on the right, and between the 6 o'clock and 10 o'clock positions on the left, with great variation. ${ }^{4}$ In addition, the number, location, and path of the lateral branches to the sacroiliac joint were not consistent, even within each segmental level in any given cadaver. ${ }^{4}$

One method of more complete denervation of the sensory branches of the sacroiliac joint is increasing the size of the lesion using internally cooled radiofrequency electrodes. Unipolar radiofrequency creates lesions $2 \mathrm{~mm}$ in diameter while bipolar radiofrequency creates larger lesions of up to $6 \mathrm{~mm}$ in diameter. ${ }^{14}$ In contrast, cooled radiofrequency denervation may offer improvement over conventional radiofrequency denervation because it produces larger lesions up to $8-10 \mathrm{~mm}$ in diameter. ${ }^{10}$

The use of cooled radiofrequency has been demonstrated in a number of studies. Kapural et al published a case series of 26 patients who underwent sacroiliac joint radiofrequency denervation using the SInergy ${ }^{\mathrm{TM}}$ system. ${ }^{15}$ The outcomes were positive, with reduction in pain scores and functional improvement at 3-4 months after the procedure. Fifty-eight percent of the patients experienced at least a two-point decrease in visual analog pain score. ${ }^{15} \mathrm{~A}$ randomized placebocontrolled trial evaluated the use of cooled radiofrequency denervation in 28 patients with sacroiliac joint pain. ${ }^{16}$ One, three, and six months after the procedure, 11 (79\%), nine 
(64\%), and eight (57\%) radiofrequency-treated patients experienced pain relief of at least $50 \%$ and significant functional improvement. In contrast, only two patients (14\%) in the placebo group experienced significant improvement at their one-month follow-up, and none experienced benefit three months after the procedure. ${ }^{16}$ Another randomized, placebocontrolled study including 51 subjects similarly showed statistically significant reductions in pain, physical function, and disability, as well as improved quality of life in the group that had received cooled radiofrequency treatment for sacroiliac joint pain when compared with the sham group. ${ }^{17}$ Treatment success was defined as a $\geq 50 \%$ reduction in NRS pain, corroborated by either a 10-point improvement in the Short Form SF-36 for Bodily Pain or a 10-point improvement in the Oswestry Disability Index, which was achieved in 59\% of treated patients at nine months post-procedure. A much larger case series involving a review of 105 patient charts was recently published. ${ }^{18}$ Long-term efficacy was demonstrated in patients who were followed up for 12-20 months after the procedure. Forty-eight percent of these patients had more than a $50 \%$ reduction in visual analog pain scores and $85 \%$ reported improved quality of life. The success rate for cooled radiofrequency in our case series is similar to that reported for this larger case series.

We acknowledge that there are some limitations to this study, in that it was a retrospective review with no placebocontrol or sham-control group. There was also no comparison with conventional radiofrequency treatment for sacroiliac joint pain, so we cannot conclude that cooled radiofrequency is superior to conventional radiofrequency. No serious complications or side effects were observed in our patients. This is consistent with other published reports of cooled radiofrequency denervation for the sacroiliac joint.

\section{Conclusion}

To the authors' knowledge, this is the first report in an Asian population showing that cooled radiofrequency denervation of the lateral sacral branches using the SInergy ${ }^{\mathrm{TM}}$ system is an effective treatment option for sacroiliac joint pain. Good long-term outcomes at 24 months can be achieved.

\section{Disclosure}

The author reports no conflicts of interest in this work.

\section{References}

1. Schwarzer AC, Aprill CN, Bogduk N. The sacroiliac joint in chronic low back pain. Spine. 1995;20:31-37.

2. Merskey H, Bogduk N. Classification of Chronic Pain: Descriptions of Chronic Pain Syndrome and Definitions of Pain Terms, 2nd ed. Seattle, WA: IASP Press; 1993.

3. Cohen SP. Sacroiliac joint pain: a comprehensive review of anatomy, diagnosis, and treatment. Anesth Analg. 2005;101:1440-1453.

4. Yin W, Willard F, Carreiro J, Dreyfuss P. Sensory stimulationguided sacroiliac joint radiofrequency neurotomy: technique based on neuroanatomy of the dorsal sacral plexus. Spine. 2003;28: 2419-2425.

5. Ferrante FM, King LF, Roche EA, et al. Radiofrequency sacroiliac joint denervation for sacroiliac syndrome. Reg Anesth Pain Med. 2001;26: 137-142.

6. Burnham RS, Yasui Y. An alternative method of radiofrequency neurotomy of the sacroiliac joint: a pilot study of the effect of pain, function, and satisfaction. Reg Anesth Pain Med. 2007;32:12-19.

7. Watanabe I, Masaki R, Min N, et al. Cooled-tip ablation results in increased radiofrequency power delivery and lesion size in the canine heart: importance of catheter-tip temperature monitoring for prevention of popping and impedance rise. J Interv Card Electrophysiol. 2002;6: 9-16.

8. Farrar JT, Young JP Jr, LaMoreaux L, Werth JL, Poole RM. Clinical important of changes in chronic pain intensity measured on an 11-point numerical pain rating scale. Pain. 2001;94:149-158.

9. Sacroiliac Joint Neurotomy Treatment for SIJS [webpage on the Internet]. Kimberly-Clark Worldwide, Inc. Available from: https://www. kcdigestivehealth.com/rfpainmanagement/pages/sinergy/si-doctors/ sij-neurotomy-treatment/the-procedure.html. Accessed July 2, 2011.

10. Lorentzen T. A cooled needled electrode for radiofrequency tissue ablation: thermodynamic aspects of improved performance compared with conventional needle design. Acad Radiol. 1996;3:556-563.

11. Haemmerich D, Chachati L, Wright AS, et al. Hepatic radiofrequency ablation with internally cooled probes: effect of coolant temperature on lesion size. IEEE Trans Biomed Eng. 2003;50:493-500.

12. Vallejo R, Benyamin RM, Kramer J, Stanton G, Joseph NJ. Pulsed radiofrequency denervation for the treatment of sacroiliac joint syndrome. Pain Med. 2006;7:429-434.

13. Cohen SP, Abdi S. Lateral branch blocks as a treatment for sacroiliac joint pain: a pilot study. Reg Anesth Pain Med. 2003;28:113-119.

14. Pino CA, Hoeft MA, Hofsee C, Rathmell JP. Morphologic analysis of bipolar radiofrequency lesions: implications for treatment of the sacroiliac joint. Reg Anesth Pain Med. 2005;30:335-338.

15. Kapural L, Nageeb F, Kapural M, Cata JP, Narouze S, Mekhail N. Cooled radiofrequency system for the treatment of chronic pain from sacroiliitis: the first case series. Pain Pract. 2008;8:348-354.

16. Cohen SP, Hurley RW, Buckenmaier CC 3rd, Kurihara C, Morlando B, Dragovich A. Randomized placebo-controlled study evaluating lateral branch radiofrequency denervation for sacroiliac joint pain. Anesthesiology. 2008;109:279-288.

17. Patel N, Gross A, Brown L, Gekht G. A randomized, placebo-controlled study to assess the efficacy of lateral branch neurotomy for chronic sacroiliac joint pain. Pain Med. 2012;13:383-398.

18. Stelzer W, Aiglesberger M, Stelzer D, Stelzer V. Use of cooled radiofrequency lateral branch neurotomy for the treatment of sacroiliac joint-mediated low back pain: a large case series. Pain Med. 2013;14: $29-35$. 
Journal of Pain Research

\section{Publish your work in this journal}

The Journal of Pain Research is an international, peer-reviewed, open access, online journal that welcomes laboratory and clinical findings in the fields of pain research and the prevention and managemen of pain. Original research, reviews, symposium reports, hypothesis formation and commentaries are all considered for publication.
Dovepress

The manuscript management system is completely online and includes a very quick and fair peer-review system, which is all easy to use. Visit http://www.dovepress.com/testimonials.php to read real quotes from published authors.

\footnotetext{
Submit your manuscript here: http://www.dovepress.com/journal-of-pain-research-journal
} 